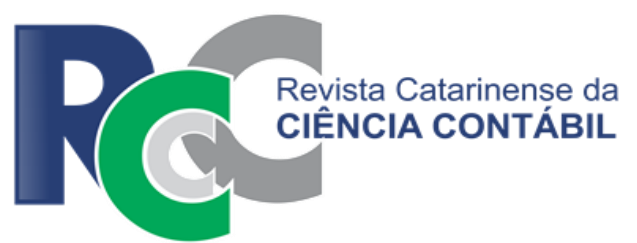

Revista Catarinense da Ciência Contábil, ISSN 1808-3781 - eISSN 2237-7662.

Florianópolis, SC, v. 16 , n. 48 , p. 52-68, maio/ago. 2017

doi: $10.16930 / 2237-7662 /$ rccc.v16n48.2402 Disponível em http://revista.crcsc.org.br

\title{
ÍNDICE DE DISCLOSURE AMBIENTAL (IDA): ANÁLISE DA APLICAÇÃO DE INDICADOR DESENVOLVIDO A PARTIR DA ÓTICA DE ESPECIALISTAS NO BRASIL*
}

\author{
INDEX OF ENVIRONMENTAL DISCLOSURE (IDA): ANALYSIS OF THE \\ APPLICATION OF INDICATOR DEVELOPED FROM \\ THE EXPERT PERSPECTIVE IN BRAZIL
}

\begin{abstract}
STELLA MARIS LIMA ALTOÉ
Doutoranda em Contabilidade na Universidade Federal do Paraná (UFPR). Professora na Universidade Estadual do Centro-Oeste (UNICENTRO). Endereço: Rua Padre Salvador, 875 / Santa Cruz | 85015-430 | Guarapuava/PR | Brasil.

E-mail: stella.altoe@gmail.com
\end{abstract}

\section{LUIZ PANHOCA}

Doutor em Controladoria e Contabilidade pela Universidade de São Paulo (USP). Professor na Universidade Federal do Paraná (UFPR). Endereço: Av. Prefeito Lothário Meissner, 632 / Jardim Botânico | 80210-170 / Curitiba/PR / Brasil.

E-mail: panhoca.luiz@gmail.com

\section{MÁRCIA MARIA DOS SANTOS BORTOLOCCI ESPEJO}

Doutora em Controladoria e Contabilidade pela Universidade de São Paulo (USP). Professora na Universidade Federal do Mato Grosso do Sul (UFMS). Endereço: Av. Costa e Silva, s/n / Cidade Universitária / 79070-900 / Campo Grande/MS / Brasil.

E-mail: marciabortolocci@gmail.com

\section{RESUMO}

As empresas preocupam-se em divulgar informações ambientais com a finalidade de transmitirem aos stakeholders uma "imagem" ambientalmente correta. O estudo objetiva aplicar o Índice de Disclosure Ambiental (IDA) aos Relatórios de Sustentabilidade no setor de papel e celulose no Brasil. Tal indicador foi desenvolvido por Bachmann, Carneiro e Espejo (2013), por meio da técnica Delphi, com pesquisadores brasileiros da área de sustentabilidade. Caracterizada como descritiva e exploratória, a análise de conteúdo foi realizada com o auxílio do software Atlas.ti a partir da categorização do IDA. Os resultados demonstraram que os Relatórios de Sustentabilidade contemplam tanto as categorias como os itens que compõem o IDA, com ressalva para a Cia. Melhoramentos de São Paulo que não evidenciou excertos da categoria informações financeiras ambientais. Os achados indicam que a Celulose Irani foi a organização cujo disclosure ambiental estava mais alinhado ao indicador proposto por Bachmann et al. (2013), apresentando um percentual de $71 \%$ de evidenciação (IDA segregado), seguido pela Fibria Celulose (64\%), Klabin (50\%) e Cia. Melhoramentos de São Paulo (36\%). Conclui-se que os resultados desta pesquisa fortalecem o IDA, favorecendo a consolidação teórica e empírica dos aspectos de disclosure ambiental, ao mesmo tempo em que propõem uma maior amplitude da discussão no escopo internacional sobre a validade

* Artigo aprovado no XV Congresso USP de Controladoria e Contabilidade, realizado de 29 a 31 de julho de 2015.

Submissão em 21/02/2017. Revisão em 16/03/2016. Aceito em 29/06/2017. 
desse indicador voltado à sustentabilidade. Portanto, observa-se a relevância das organizações desenvolverem projetos, indicadores e terem iniciativas direcionadas à evidenciação das informações ambientais, considerando que os investimentos relacionados à redução dos impactos ambientais são benéficos à entidade e a todas as partes interessadas na informação.

Palavras-chave: Índice de Disclosure Ambiental (IDA). Relatório de Sustentabilidade. Análise de Conteúdo.

\begin{abstract}
Companies are concerned with disclosing environmental information in order to convey to stakeholders an environmentally sound "image". The study aims to apply the Environmental Disclosure Index (IDA) to Sustainability Reports in the paper and pulp sector in Brazil. This indicator was developed by Bachmann, Carneiro and Espejo (2013), with Brazilian researchers in the area of sustainability, using the Delphi technique. Characterized as descriptive and exploratory, the content analysis was performed using the Atlas.ti software from the IDA categorization. The results show that Sustainability Reports include both the categories and the items that make up IDA, except for Cia. Melhoramentos de São Paulo, which failed to show excerpts from the environmental financial information. The findings indicate that Celulose Irani was the organization whose environmental disclosure was more aligned with the indicator proposed by Bachmann et al. (64\%), followed by Fibria Celulose (64\%), Klabin (50\%) and Cia. Melhoramentos de São Paulo (36\%). It is concluded that the results of this research strengthen the IDA, favoring the theoretical and empirical consolidation of the aspects of environmental disclosure, while proposing a wider range of international discussion on the validity of this indicator aimed at sustainability. Therefore, it is observed the relevance of organizations to develop projects, indicators and initiatives aimed at the disclosure of environmental information, considering that investments related to the reduction of environmental impacts are beneficial to the entity and all information stakeholders.
\end{abstract}

Keywords: Environmental Disclosure Index (IDA). Sustainability Report. Content Analysis.

\title{
1 INTRODUÇÃO
}

A contabilidade ambiental é uma parte da contabilidade que analisa atividades, métodos, sistemas, relatórios de impactos financeiros e impactos ecológicos de um sistema econômico (Schaltegger \& Burrit, 2000). Na perspectiva dos relatórios, a evidenciação das informações ambientais no Brasil não possui um marco regulatório definido. Entretanto, a pressão exercida pelos stakeholders, sobretudo, nas companhias que apresentam atividades de alto impacto ambiental, induzem ao disclosure voluntário (Nossa, 2002).

Diante do caráter voluntário do disclosure ambiental é relevante entender as motivações para divulgação das informações ambientais (Yamamoto \& Salotti, 2006), pois essa evidenciação contribui para a geração de valor agregado, elevando a confiança e o comprometimento para com as partes interessadas (Borges, Rosa, \& Ensslin, 2010). Além disso, a divulgação de informações ambientais e o desempenho econômico têm uma correlação intrínseca; os arranjos institucionais do sistema de divulgação de informações ambientais, necessariamente, promovem o desempenho da economia (Zhongfu, Jianhui, \& Pinglin, 2011). Nesse cenário, a Bovespa desenvolveu o Índice de Sustentabilidade Empresarial (ISE) que contempla as companhias que se preocupam com o desenvolvimento sustentável da sociedade (BM\&FBovespa, 2014).

Salienta-se que a implantação de processos sustentáveis é um dos grandes desafios das organizações. Possuem o objetivo de reduzir a poluição e minimizar a utilização dos recursos naturais que são escassos (Souza, Rásia, \& Jacques, 2010). Dalmoro, Venturini e Pereira (2009) relatam que a busca desregrada por resultados econômicos no curto prazo por algumas empresas ocasionaram grandes impactos ecológicos com reflexos nas partes relacionadas. Nesse sentido, as questões sociais e ambientais no âmbito corporativo têm influenciado a elevação das pesquisas na área de contabilidade ambiental, sobretudo nos 
aspectos referentes a disclosure (Nascimento, Santos, Salotti, \& Múrcia, 2009). A ação socialmente responsável das entidades já ultrapassou o estágio de mera tendência e a sustentabilidade vem se tornando uma visão estratégica de negócios de longo prazo que incorpora as dimensões econômica, social e ambiental (Kassai, Há, \& Carvalho, 2011).

Costa e Marion (2007) analisaram o disclosure ambiental e observaram que a ausência de uniformidade das informações prejudica a análise dos relatórios. Souza et al. (2010) investigaram as informações ambientais das empresas que compõem o ISE nos segmentos de energia elétrica, química e siderurgia e metalurgia. Os resultados sugerem que no Balanço Social há maiores evidenciações ambientais, comparativamente ao Relatório da Administração e as Notas Explicativas; ainda, observa-se que a utilização de indicadores ambientais é pouco explorada nesses segmentos empresariais.

Roumeliotis e Alperstedt (2014) analisaram nos Relatórios de Sustentabilidade os princípios e indicadores ambientais das empresas de geração de energia elétrica em Santa Catarina (SC), de forma a atender aos requisitos do GRI. Para tal, utilizaram análise de conteúdo. Os resultados evidenciaram que a estrutura do Relatório precisa de evolução, para que haja maior aderência dos fatores relacionados aos princípios e aos graus dos indicadores ambientais.

Bachmann et al. (2013) elencaram atributos ambientais, de acordo com o grau de importância de disclosure para composição de um indicador brasileiro que avaliasse a qualidade de evidenciação de informações ambientais. Nessa perspectiva, a contribuição científica da presente investigação é a aplicação do indicador brasileiro, denominado de Índice de Disclosure Ambiental (IDA) ao segmento de papel e celulose.

Portanto, a questão que orienta este estudo é: qual a aplicação do IDA aos Relatórios de Sustentabilidade? O objetivo da pesquisa é apresentar os resultados da aplicação do IDA as empresas pertencentes ao setor de papel e celulose. Assim, espera-se constatar nesta pesquisa se as empresas do segmento de papel e celulose contemplam as categorias de análise definidas pelo IDA e qual o conteúdo que está sendo evidenciado por essas companhias em seus Relatórios de Sustentabilidade.

Justifica-se a relevância deste estudo considerando que a sustentabilidade representa um novo escopo de investigação no "mundo dos negócios", sua atuação otimiza a utilização dos recursos naturais e contribui para a integridade do planeta (BM\&FBovespa, 2014). Ainda, espera-se com esta pesquisa colaborar para o conhecimento científico, dado o ineditismo do indicador aplicado, bem como divulgá-lo nacionalmente a fim de possibilitar a ampliação da massa crítica sobre o tema sustentabilidade.

Pesquisas atreladas à sustentabilidade ambiental no setor de papel e celulose são relevantes, tendo em vista que esse segmento é dependente da natureza, e que essa possui recursos escassos. Além disso, caso as empresas não se conscientizem dos impactos gerados no processo industrial, a continuidade do setor poderá ser comprometida (Gasparino \& Ribeiro, 2007). Logo, observa-se a necessidade de uma postura socialmente correta pelas entidades.

Nossa (2002) realizou análise de conteúdo nos relatórios ambientais do setor de papel e celulose em nível internacional. Os achados do estudo revelaram que o disclosure ambiental nas empresas do segmento de papel e celulose diferenciam-se em decorrência do porte, país de localização e tipo de relatório financeiro ou específico. Nessa mesma linha de investigação, a presente pesquisa busca contribuir para 0 avanço dos estudos relacionados à sustentabilidade.

\section{DISCLOSURE AMBIENTAL E O IDA}

Questões ambientais são frequentemente discutidas (Zeng, Xu, Dong, \& Tam, 2010; Zhongfu et al., 2011; Ashcroft, 2012; Momin, 2013; Lu \& Abeysekera, 2014). Os aspectos centrais referem-se ao comprometimento por parte das organizações no que concerne aos impactos ambientais oriundos das atividades fins das empresas (Lu \& Abeysekera, 2014). Nossa (2002) esclarece que o disclosure ambiental, também denominado de evidenciação ambiental, pode ser obrigatório ou voluntário; o primeiro refere-se às imposições legais e normativas; por outro lado, o voluntário é decorrente das escolhas dos gestores. 
No Brasil, não há regulamentação para o disclosure ambiental, portanto, a divulgação por parte das entidades apresenta-se como voluntária. As Leis n. 6.404/76 e n. 11.638/07 não mencionam especificidades para a divulgação desses aspectos. Entretanto, o Parecer de Orientação n. 15/87 da Comissão de Valores Mobiliários (CVM), a Norma e Procedimento de Auditoria n. 11 do Instituto dos Auditores Independentes do Brasil (IBRACON) e a Resolução n. 1.003/04 do Conselho Federal de Contabilidade (CFC) apresentam diretrizes para a divulgação das informações ambientais (Beuren, Santos, \& Gubiani, 2013).

A Bovespa em dezembro de 2005 criou o Índice de Sustentabilidade Empresarial (ISE), que busca avaliar de forma integrada diferentes escopos da sustentabilidade, cujo foco é induzir as entidades a terem boas práticas ambientais. Ressalta-se que na composição do ISE, uma das dimensões refere-se ao Tripple Bottom Line que considera três perspectivas de análise: i) econômica; ii) social; e iii) ambiental. A dimensão econômica analisa a eficácia da alocação dos recursos de produção; a social considera o desenvolvimento humano, especificamente os aspectos referentes a remuneração dos empregados, ambiente seguro; e a vertente ambiental centra-se nos aspectos relativos ao ecossistema e recursos naturais (BM\&FBovespa, 2014).

Nesse sentido, a maior divulgação dos aspectos ambientais contribui para a criação de uma imagem ambientalmente correta, redução do custo de capital e aumento da liquidez das ações. É um diferencial para as organizações que adotam essa postura (Rover, Múrcia, Borba, \& Vicente, 2008). Ainda, a divulgação de informações ambientais favorece o desenvolvimento da imagem corporativa (Gray \& Bebbington, 2001) e colabora para a vantagem competitiva (Porter, 1993; Aaker; 2001; Tachizawa, 2002).

Com relação às pesquisas com enfoque ambiental, no Brasil, Ribeiro (1992) marca o seu início, ao investigar o perfil da divulgação das informações ambientais pela contabilidade no escopo nacional e internacional. Nossa (2002) analisou em empresas brasileiras e estrangeiras pertencentes ao setor de papel e celulose o disclosure ambiental. Os achados vão ao encontro da teoria, considerando que a variação da evidenciação ambiental ocorre conforme o tamanho da empresa e do país.

Borba, Rover e Múrcia (2006) compararam a evidenciação de informações ambientais do Brasil com a dos Estados Unidos. Os resultados comprovaram discrepâncias no que concerne ao volume de informações divulgadas por esses países. Rover et al. (2008) verificaram as informações ambientais voluntárias divulgadas por empresas pertencentes a setores de alto impacto. Para tanto, categorias de análises foram estabelecidas. Seus resultados corroboram a Teoria do Disclosure Voluntário que se refere ao disclosure que excede ao que é recomendado pela regulação e representa uma escolha livre (free choice) por parte dos gestores em comunicar informações adicionais para o processo decisório dos usuários internos e externos (Múrcia \& Santos, 2009).

O periódico "Accounting, Auditing and Accountability Journal" realizou edições especiais sobre temas relacionados ao meio ambiente (Rover et al., 2008). A seguir, a Tabela 1 apresenta estudos realizados na perspectiva da evidenciação ambiental a partir de 2010.

Tabela 1

\section{Estudos internacionais}

\begin{tabular}{l|c}
\hline \multicolumn{1}{c|}{ Estudos internacionais } & Autor (es) \\
\hline $\begin{array}{l}\text { As Informações Ambientais Corporativas (IDE) referem-se a informações relacionadas ao } \\
\text { ambiente natural, proteção ambiental e utilização dos recursos. Tais informações foram }\end{array}$ & $\begin{array}{c}\text { Zeng, Xu, } \\
\text { Dong e Tam } \\
\text { analisadas em 871 indústrias listadas na bolsa chinesa. Nas discussões são apresentadas as } \\
\text { relações entre o IDE, comparativamente ao setor industrial, tamanho da empresa e propriedade } \\
\text { da entidade. Os resultados revelam a relação negativa entre o nível de mercantilização e o IDE. }\end{array}$ \\
\hline $\begin{array}{l}\text { Esta pesquisa constata que a divulgação de informação ambiental tem um efeito positivo sobre } \\
\text { o desempenho econômico. Assim as empresas que divulgam suficientemente a sua informação } \\
\text { ambiental têm melhor desempenho econômico. }\end{array}$ & $\begin{array}{c}\text { Zhongfu, } \\
\text { Jianhui e } \\
\text { Pinglin (2011) }\end{array}$ \\
\hline
\end{tabular}

Continua 


\begin{tabular}{|c|c|}
\hline Estudos internacionais & Autor (es) \\
\hline $\begin{array}{l}\text { Este estudo foi realizado em empresas dos Estados Unidos e Canadá, com o propósito de } \\
\text { discutir as influências para a elaboração da divulgação ambiental. O conteúdo da divulgação } \\
\text { ambiental dos relatórios anuais foram avaliados com base nas diretrizes de relatórios } \\
\text { ambientais publicados pelo Instituto Americano de Contadores Públicos e do Instituto } \\
\text { Canadense de Revisores Oficiais de Contas. Os resultados indicam que as empresas norte- } \\
\text { americanas, apresentam maior nível de divulgação ambiental do que as empresas } \\
\text { canadenses. }\end{array}$ & Ashcroft (2012) \\
\hline $\begin{array}{l}\text { Este artigo explora as percepções de Divulgação Social Corporativa (CSD) em organizações } \\
\text { não-governamentais no contexto de um país em desenvolvimento: Bangladesh. Entrevistas } \\
\text { semiestruturadas foram realizadas em ONGs sociais e ambientais selecionadas. Os } \\
\text { resultados sugerem que as empresas precisam se engajar no desenvolvimento social para } \\
\text { melhorar seu desempenho social, a fim de satisfazer as suas responsabilidades sociais e } \\
\text { ambientais para o povo de Bangladesh. }\end{array}$ & Momin (2013) \\
\hline $\begin{array}{l}\text { Investigaram a influência das partes interessadas e as características sociais e ambientais de } \\
\text { empresas chinesas listadas como socialmente responsáveis. Os resultados indicaram que as } \\
\text { divulgações relacionadas a aspectos sociais e ambientais têm associação positiva e } \\
\text { significativa com o tamanho da empresa, rentabilidade e classificação da indústria. }\end{array}$ & $\begin{array}{l}\text { Lu e } \\
\text { Abeysekera } \\
\text { (2014) }\end{array}$ \\
\hline
\end{tabular}

Nota. Fonte: os autores, com base nas obras citadas (2017).

Observa-se a abrangência dos estudos internacionais referentes a questões ambientais (Zeng et al., 2010; Zhongfu et al., 2011; Ashcroft, 2012; Momin, 2013; Lu \& Abeysekera, 2014). Com o intuito de contribuir para o avanço científico das pesquisas brasileiras relacionadas à evidenciação ambiental, discute-se a seguir a composição do Índice de Disclosure Ambiental desenvolvido por pesquisadores brasileiros denominado IDA.

O estudo de Bachmann et al. (2013), publicado na Revista de Contabilidade e Organizações, suscitou a elaboração da presente investigação. A partir da percepção de especialistas de contabilidade e sustentabilidade, os autores, por meio de rodadas Delphi, construíram o IDA, indicador composto por dez atributos de características ambientais. $\mathrm{Na}$ opinião dos especialistas, esses atributos, em ordem crescente, refletem na praticidade e representatividade da qualidade das informações ambientais.

\section{Tabela 2}

\section{Composição do Indicador de Disclosure Ambiental (IDA) \\ Composição do IDA}

1 - Impactos ambientais dos produtos e processos (poluição atmosférica, das águas, sonora, visual)

2 - Informações sobre resíduos e desperdícios

3 - Estabelecimento de metas e objetivos ambientais

4 - Programa de gestão ambiental (longo prazo)

5 - Declaração das políticas empresariais ambientais

6 - Uso eficiente / Reutilização da água

7 - Auditoria ambiental

8 - Práticas contábeis de itens ambientais

9 - Reserva para proteção ambiental

10 - Custos e/ou despesas ambientais

Nota. Fonte: Bachmann, R. K., Carneiro, L. M., \& Espejo, M. M. dos S. B. (2013). Evidenciação de informações ambientais: proposta de um indicador a partir da percepção de especialistas. Revista de Contabilidade e Organizações, 7(17), 36-47.

Para os autores, o estudo possibilita o entendimento dos atributos ambientais que são essenciais de serem divulgados. Ainda, revela que os aspectos qualitativos como, por exemplo, "impactos ambientais de produtos e processos" e "informações sobre resíduos", apresentaram elevado grau de importância. Como perspectiva de novos estudos, os autores sugerem que o 
IDA possa ser validado em uma série de empresas. Essa sugestão alinha-se com o propósito do presente estudo.

\section{METODOLOGIA DA PESQUISA}

Esta pesquisa caracteriza-se como descritiva e exploratória, à medida que busca identificar a aplicação do IDA aos relatórios de sustentabilidade. Avaliou-se somente as empresas pertencentes ao setor de papel e celulose com ações negociadas na BM\&FBovespa, Tabela 3.

Tabela 3

\section{Carteira Bovespa setor de papel e celulose}

\begin{tabular}{l|l}
\hline Celulose Irani & Santher Fab. de Papel Sta. Therezinha \\
\hline Cia. Melhoramentos de São Paulo & Suzano Holding \\
\hline Fibria Celulose & Suzano Papel e Celulose \\
\hline Klabin & \\
\hline
\end{tabular}

Nota. Fonte: BM\&FBovespa. (2014). Indice de Sustentabilidade Empresarial (ISE).

Após seleção das empresas, e para operacionalização deste estudo, os dados foram coletados no Relatório de Sustentabilidade referente ao ano base 2013. Tais relatórios foram capturados em outubro de 2014 nos sites das companhias. O Relatório de Sustentabilidade, também denominado de Integrado, reporta informações e resultados relacionados às dimensões social, ambiental e de governança corporativa. Seu diferencial consiste em ser um meio rápido de acesso a essas informações (BM\&Fbovespa, 2014).

Nesse momento, constatou-se que a companhia Santher Fab. de Papel Sta. Therezinha não publica este relatório e no sítio da Suzano Papel e Celulose só estavam disponíveis os Relatórios de Sustentabilidade até o ano de 2012. Isso posto, realizou-se contato por meio de e-mail com a companhia Suzano Papel e Celulose. Entretanto, não se obteve retorno. Dessa forma, obtiveram-se como amostra final quatro companhias: i) Celulose Irani; ii) Cia. Melhoramento de São Paulo; iii) Fibria Celulose; e iv) Klabin.

Para analisar a aplicação do IDA aos Relatórios de Sustentabilidade, utilizou-se a técnica de análise de conteúdo, que busca revelar a descrição do conteúdo das mensagens, a partir de procedimentos sistemáticos e objetivos (Bardin, 2004). Fauzi (2009) e Nossa (2002) também utilizaram essa metodologia em seus estudos, ao discutirem assuntos de cunho ambiental.

Assim, conforme proposto por Bachmann et al. (2013), os 10 componentes do IDA foram distribuídos em 4 categorias ambientais: i) impacto dos produtos e processos; ii) políticas ambientais; iii) sistemas de gerenciamento ambiental e; iv) informações financeiras ambientais, conforme Tabela 4.

Tabela 4

Estrutura conceitual para o disclosure ambiental

\begin{tabular}{c|l}
\hline Categorias Ambientais & \multicolumn{1}{c}{ Composição do IDA } \\
\hline \multirow{4}{*}{\begin{tabular}{c} 
Impacto dos Produtos e $\begin{array}{c}\text { Processos } \\
\text { Políticas Ambientais }\end{array}$ \\
\cline { 2 - 2 }
\end{tabular}} & $\begin{array}{l}1 \text { - Impactos ambientais dos produtos e processos (poluição atmosférica, das } \\
2 \text { - Informações sobre resíduos e desperdícios }\end{array}$ \\
\cline { 2 - 2 } & 6 - Uso eficiente / Reutilização da água \\
\hline & 3 - Estabelecimento de metas e objetivos ambientais \\
\cline { 2 - 2 } & 5 - Declaração das políticas empresariais ambientais \\
\hline
\end{tabular}


Tabela 4 (continuação)

\begin{tabular}{c|l}
\hline Categorias Ambientais & Composição do IDA \\
\hline $\begin{array}{c}\text { Sistemas de Gerenciamento } \\
\text { Ambiental }\end{array}$ & 4 - Programa de gestão ambiental (longo prazo) \\
\cline { 2 - 2 } & 7 - Auditoria ambiental \\
\hline \multirow{3}{*}{$\begin{array}{c}\text { Informações Financeiras } \\
\text { Ambientais }\end{array}$} & 8 - Práticas contábeis de itens ambientais \\
\cline { 2 - 2 } & 9 - Reserva para proteção ambiental \\
\cline { 2 - 2 } & 10 - Custos e/ou despesas ambientais \\
\hline
\end{tabular}

Nota. Fonte: Adaptado de Múrcia, F. D. R., Rover, S., Lima, I., Fávero, L. P. L., \& Lima, G. A. S. F. de. (2008). 'Disclosure Verde' nas demonstrações contábeis: características da informação ambiental e possíveis explicações para a divulgação voluntária. Contabilidade, Revista UnB Contábil, 11, 260-278; Bachmann, R. K., Carneiro, L. M., \& Espejo, M. M. dos S. B. (2013). Evidenciação de informações ambientais: proposta de um indicador a partir da percepção de especialistas. Revista de Contabilidade e Organizações, 7(17), 36-47. (2013).

Para associar o disclosure ambiental aos indicadores do IDA e suas categorias às companhias pertencentes ao setor de papel e celulose, utilizou-se o software Atlas. Ti versão 7.5.2. Esse software possibilitou a categorização e interligação das informações ambientais presentes nos Relatórios de Sustentabilidade, por meio da criação de um projeto na unidade denominada hermenêutica que compõe os documentos primários (P-Docs), as citações (Quotes) e os códigos (Codes). A partir desses elementos o Atlas. Ti possibilita a ilustração das relações observadas pelo pesquisador por meio da construção de teias de relacionamento. Sendo assim, para obtenção desses resultados, realizou-se leitura dos Relatórios de Sustentabilidade e classificou-se os excertos do texto aos dez atributos que compõem o IDA. Ressalta-se que algumas categorias foram segregadas, por tratarem de diferentes abordagens. O Tabela 5 evidencia a composição do IDA (segregado) utilizada para a análise de conteúdo.

\section{Tabela 5}

\section{Segregação do IDA para análise de conteúdo}

\begin{tabular}{l|l}
\hline \multirow{2}{*}{ Composição do IDA } & \multicolumn{1}{c}{ Composição do IDA Segregado } \\
\hline \multirow{2}{*}{\begin{tabular}{l} 
(poluição atmosférica, das águas, sonora, visual) \\
\cline { 2 - 2 } 2
\end{tabular}} & 1.1 - Poluição atmosférica \\
\cline { 2 - 2 } 2 - Informações sobre resíduos e desperdícios & 1.2 - Poluição das águas \\
\cline { 2 - 2 } & 1.4 - Poluiçãõo sonora visual \\
\hline 3 - Estabelecimento de metas e objetivos ambientais & 2.1 - Resíduos \\
\cline { 2 - 2 } 4 - Programa de gestão ambiental (longo prazo) & 2.2 - Desperdícios \\
\hline 5 - Declaração das políticas empresariais ambientais & 4.1 - Programa ambiental \\
\hline 6 - Uso eficiente / Reutilização da água & 5.1 - Políticas ambientais \\
\hline 7 - Auditoria ambiental & 6.1 - Reutilização da água \\
\hline 8 - Práticas contábeis de itens ambientais & 7.1 - Auditoria ambiental \\
\hline 9 - Reserva para proteção ambiental & 8.1 - Práticas contábeis ambientais \\
\hline 10 - Custos e/ou despesas ambientais & 9.1 - Reserva ambiental \\
\hline
\end{tabular}

Nota. Fonte: Adaptado de Bachmann, R. K., Carneiro, L. M., \& Espejo, M. M. dos S. B. (2013). Evidenciação de informações ambientais: proposta de um indicador a partir da percepção de especialistas. Revista de Contabilidade e Organizações, 7(17), 36-47.

A partir do caminho metodológico percorrido exposto, atingiu-se o objetivo final do presente estudo, conforme relatado a seguir. 


\section{ANÁLISE DOS RELATÓRIOS DE SUSTENTABILIDADE}

\subsection{Celulose Irani}

A Celulose Irani possui capital aberto desde 1977. Suas atividades centram-se na produção de papéis para embalagem, caixas e chapas de papelão ondulado, biodegradáveis e $100 \%$ recicláveis, e resinas. Suas unidades industriais encontram-se nas cidades de Vargem Bonita (SC), Balneário Pinhal (RS), Indaiatuba (SP) e Santa Luzia (MG). Suas sedes administrativas estão localizadas em Joaçaba (SC) e São Paulo (SP), com matriz em Porto Alegre (RS) (Relatório de sustentabilidade Celulose Irani, 2013).

Quanto às categorias ambientais que compõem o IDA, verificou-se que todas foram evidenciadas no Relatório de Sustentabilidade, conforme Figura 1. Todavia, alguns itens não foram mencionados, como, por exemplo, poluição sonora, poluição visual, reserva ambiental e práticas contábeis ambientais.

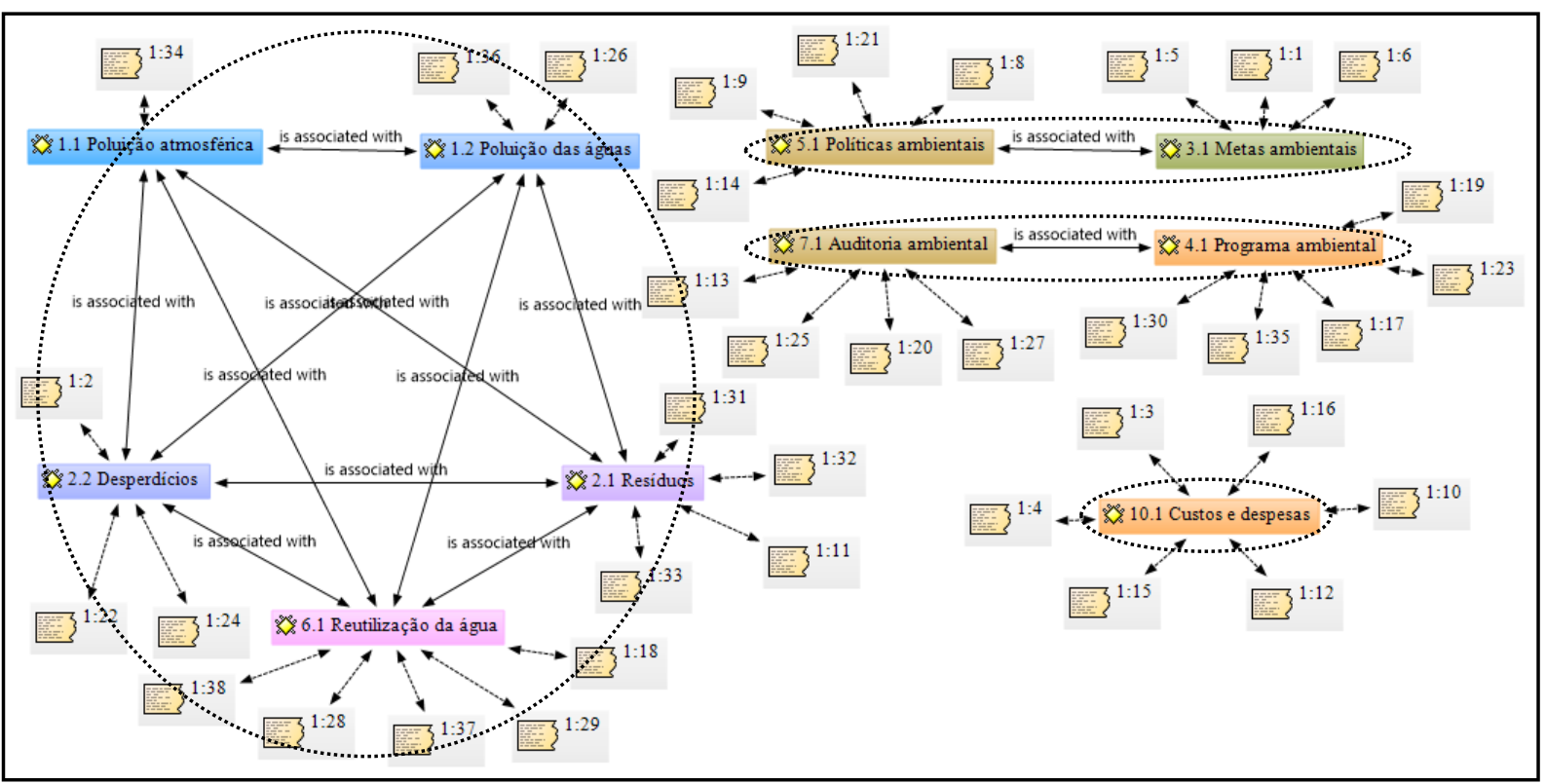

Figura 1. Aplicação do IDA na Celulose Irani

Fonte: Os autores (2017).

Com relação à categoria impacto dos produtos e processos constatou-se que no disclosure referente à poluição atmosférica a empresa remove da atmosfera uma quantidade de carbono superior à que emite, logo suas atividades apresentam carbono neutro. No que concerne à poluição das águas, em 2013 a Unidade de Resinas apresentou problemas na Estação de Tratamento de Efluentes (ETE). Verifica-se que a empresa adota procedimentos específicos para a coleta, armazenagem e destino adequado dos resíduos gerados ao longo dos processos, a partir da contratação de serviços especializados.

$\mathrm{Na}$ ótica dos desperdícios, a Celulose Irani busca a melhoria contínua dos indicadores da Análise do Ciclo de Vida (ACV) dos produtos, com o intuito de evitar os desperdícios e identificar novas oportunidades de redução de custos. Há trechos que evidenciam a prática de reutilização da água, em que a Celulose Irani afirma que o consumo de água vem reduzindo ao longo dos anos; além disso, as novas tecnologias implantadas possibilitaram o reaproveitamento da água em alguns processos por meio de circuitos fechados.

$\mathrm{Na}$ categoria políticas ambientais, a Celulose Irani evidenciou que uma de suas metas ambientais é manter o equilíbrio entre o meio ambiente e a sociedade. Paralelamente, a empresa busca criatividade e determinação para seguir avançando na redução dos impactos ambientais, especialmente com foco na reciclagem de produtos e subprodutos. Na perspectiva das políticas ambientais, a empresa assegura o compromisso com a sustentabilidade em suas ações, além de acreditar que a sustentabilidade é um fator condicional para a inovação. 
Quanto à categoria sistemas de gerenciamento ambiental, a empresa se posicionou nos aspectos relativos à auditoria ambiental e aos programas ambientais. Com relação à auditoria, a empresa evidencia adequação dos procedimentos às normas internacionais de sustentabilidade. Menciona também que são realizadas auditorias internas e externas. Especificamente na ETE, o monitoramento compreende análises de vários parâmetros e ações constantes que são desenvolvidas visando à redução do volume de efluente.

Observa-se o desenvolvimento de alguns programas como: i) Programa "Horta Familiar: cultive saúde em casa", (estimula o cultivo de alimentos orgânicos e qualidade de vida dos moradores); ii) Programa de Gerenciamento de Resíduos Sólidos (prioriza a redução, a reciclagem e a reutilização de resíduos); iii) Programa de Emissões de Fontes Fixas (objetivo de monitorar periodicamente os pontos de emissão das suas unidades industriais).

A categoria informações financeiras ambientais apresenta aspectos de disclosure referente aos custos/despesas. A empresa declara que busca ganhos com a produtividade e redução de custos nos processos. Em 2013 a desvalorização do Real impulsionou a cadeia produtiva a enfrentar novos desafios na perspectiva dos custos. No mesmo ano, a empresa obteve uma economia de $\mathrm{R} \$ 3.500,00$ reais na reutilização de substrato de produção de mudas de Pinus e eucalipto para a produção de mudas nativas.

\subsection{Cia. Melhoramentos de São Paulo}

A Cia. Melhoramentos de São Paulo elabora o Relatório de Sustentabilidade desde 2011. A atuação da empresa ocorre no segmento editorial, de manejo florestal, fibra celulósica e patrimonial, distribuídos em 3 unidades. Além da sede administrativa em São Paulo, na região da Lapa, o manejo se faz na Fazenda Florestal em Caieiras (SP), com 5 mil hectares, na Fazenda Santa Marina em Bragança Paulista (SP), com 650 hectares e na Fazenda Levantina em Camanducaia (MG), com aproximadamente 12 mil hectares. Nessa última, além do manejo florestal praticado em apenas $50 \%$ da área total, preserva os outros $50 \%$ como mata nativa (Relatório de Sustentabilidade Cia. Melhoramentos de São Paulo, 2013).

A análise dos dados revelou que três categorias ambientais - impacto dos produtos e processos; políticas ambientais e sistemas de gerenciamento ambiental - estão presentes no Relatório de Sustentabilidade da Cia. Melhoramentos de São Paulo, 2013. Quanto à categoria impacto dos produtos e processos, a empresa emitiu nota sobre ações direcionadas à reutilização da água, ressaltando que a água após ser utilizada é tratada em uma ETE. Além disso, evidenciou que investimentos foram realizados na ETE, aumentando sua capacidade de tratamento de $10 \mathrm{~m}^{3} / \mathrm{h}$ para $20 \mathrm{~m}^{3} / \mathrm{h}$.

$\mathrm{Na}$ categoria políticas ambientais, a Cia. Melhoramentos de São Paulo apresentou em seu Relatório de Sustentabilidade excertos de metas e de políticas ambientais. Observa-se que com relação às metas a empresa busca ser referência em responsabilidade socioambiental, tornar-se a maior produtora de fibra de alto rendimento para o mercado mundial até 2025, além de buscar neutralizar os impactos ambientais em suas operações, preocupando-se com a preservação e o monitoramento da biodiversidade presente em suas áreas de manejo.

Com referência as políticas ambientais, constata-se que a organização ampara-se no ideal de respeito ao meio ambiente, protegendo os ecossistemas. Portanto, pelos relatos, a entidade envolve-se em práticas de responsabilidades socioambientais. Na perspectiva dos clientes, sua política centra-se na criação de valor na cadeia de embalagem sustentável.

Outra abordagem identificada na Cia. Melhoramentos de São Paulo corresponde ao sistema de gerenciamento ambiental. Nessa categoria, a entidade evidenciou aspectos de auditoria ambiental e participação em programas de gestão ambiental. Na vertente da auditoria, a empresa segue as rígidas normas estabelecidas pelo Forest Stewardship Council (FSC), além de realizar auditorias frequentes. Outra observação verificada em 2013 pela auditoria anual, refere-se à manutenção do Selo Verde nas Fazendas de Camanducaia, o que garante a rastreabilidade da madeira desde a obtenção da matéria prima, até o consumidor final.

$\mathrm{Na}$ perspectiva dos programas ambientais, o conteúdo das informações divulgadas menciona que a organização possui um programa de melhoria genética, cuja finalidade é a seleção e obtenção de clones adaptados às condições climáticas, que contribuam para a produção de fibras de alto rendimento. Além disso, constata-se que a Cia. Melhoramentos de 
São Paulo participa de programas cooperativos vinculados ao Instituto de Pesquisa e Estudos Florestais, cujo enfoque é a melhoria do enraizamento de seus clones.

Com relação às categorias ambientais do IDA, a Cia. Melhoramentos de São Paulo dentre as entidades analisadas, foi a que apresentou a menor quantidade. Pela análise no Relatório de Sustentabilidade, alguns itens, como poluição atmosférica, poluição das águas, poluição sonora, poluição visual, resíduos, desperdícios, práticas contábeis ambientais, reserva ambiental e custos e despesas não foram mencionados.

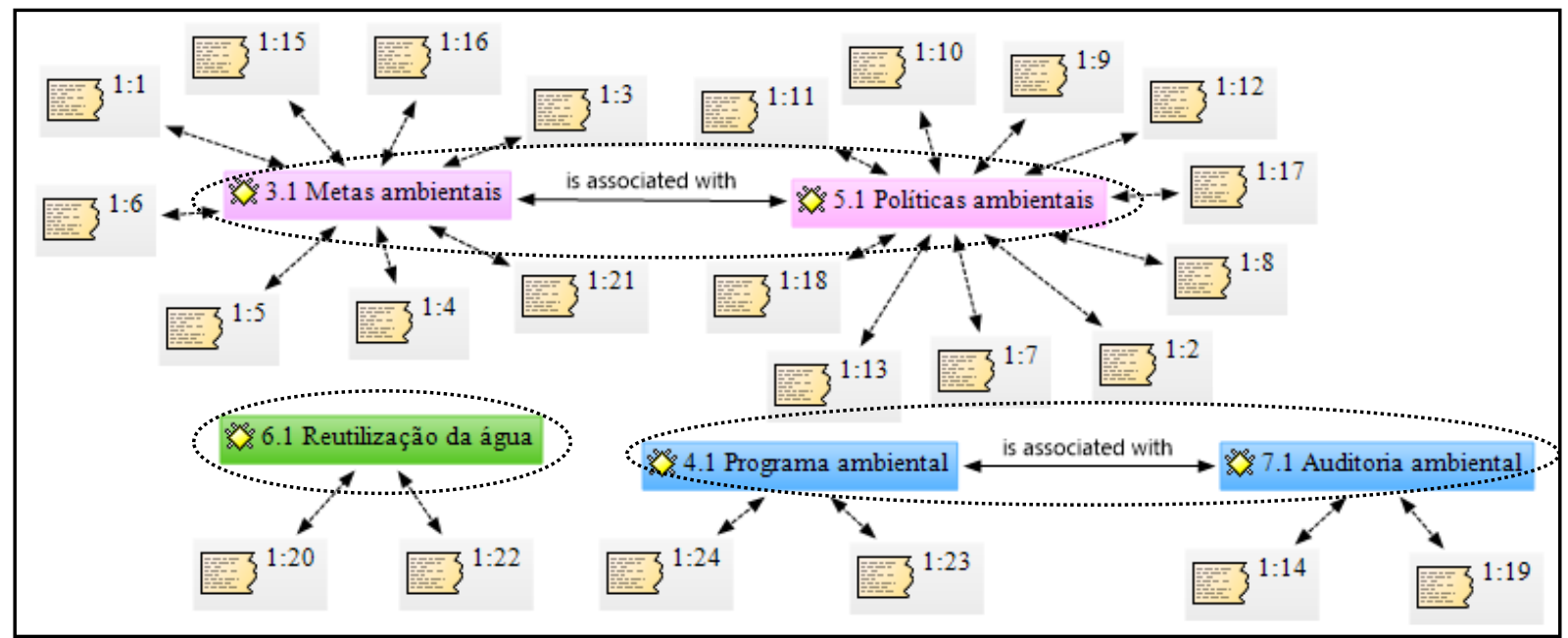

Figura 2. Aplicação do IDA na Cia. Melhoramentos de São Paulo Fonte: Os autores (2017). São Paulo.

A Figura 2 representa as categorias identificadas na análise da Cia. Melhoramentos de

\subsection{Fibria Celulose}

A Fibria Celulose foi criada em 2009, a partir da compra da Aracruz Celulose S.A. pela Votorantim Celulose e Papel S.A. É a maior produtora mundial de celulose de fibra curta de eucalipto - matéria-prima para a fabricação de papéis para higiene pessoal, impressão e escrita e usos especiais. A madeira é processada nas fábricas da companhia em Aracruz (ES), Três Lagoas (MS) e Jacareí (SP). A Fibria está presente em 242 municípios de 7 Estados brasileiros: Rio Grande do Sul, São Paulo, Rio de Janeiro, Espírito Santo, Mato Grosso do Sul, Minas Gerais e Bahia. A empresa mantém, ainda, uma quarta Unidade Industrial, a Veracel, em sociedade com o grupo sueco-finlandês Stora Enso (Relatório de Sustentabilidade Fibria Celulose, 2013).

Pela Figura 3, observa-se que todas as categorias ambientais que compõem o IDA foram identificadas no Relatório de Sustentabilidade da Fibria. Ressalta-se que alguns itens dessas categorias não foram identificados na análise realizada, a saber: i) poluição das águas; ii) poluição sonora; iii) poluição visual; iv) desperdícios; e v) reserva ambiental.

Quanto à categoria impactos dos produtos e processos, a entidade evidenciou aspectos de poluição atmosférica, resíduos e reutilização da água. Alguns trechos enfatizam que a área total afetada por incêndios foi de 7.950 hectares, sendo que 4.445,1 hectares das florestas queimadas encontravam-se em áreas de preservação. No que concerne a resíduos, a empresa enfatiza que uma de suas prioridades no processamento industrial é aproveitar ao máximo os resíduos sólidos e até 2025 buscar a redução de 91\% do volume de resíduos destinados a aterros industriais. Na Unidade Jacareí, por exemplo, constata-se o aproveitamento do resíduo (fibra) que antes era descartado, elevando a produtividade da fábrica e proporcionando uma economia anual de cerca de R $\$ 500$ mil. Além disso, a empresa utiliza o corretivo de solo a partir do aproveitamento de resíduos industriais, o que gera economia. 


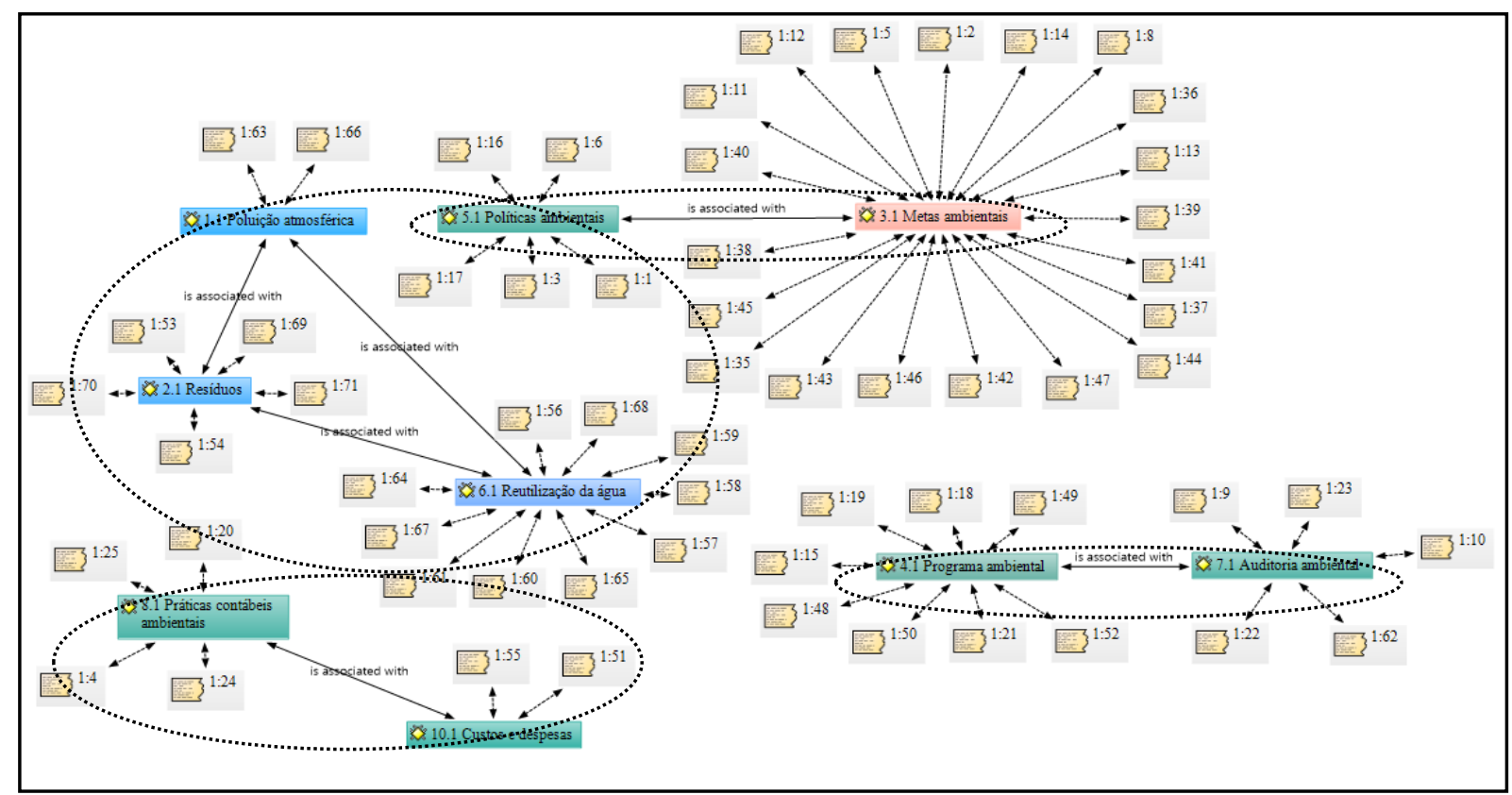

Figura 3. Aplicação do IDA na Fibria Celulose

Fonte: Os autores (2017).

Observa-se a preocupação da Fibria Celulose quanto ao uso eficiente da água. Nos trechos do Relatório de Sustentabilidade, percebe-se que a entidade busca garantir a quantidade e a qualidade de águas necessárias para suas atividades florestais e industriais assegurando o abastecimento às comunidades. Em 2013, a Fibria ampliou o monitoramento dos recursos hídricos com o propósito de identificar gargalos que pudessem interferir na oferta de água às comunidades. Ressalta-se que, em 2013, um projeto inovador foi desenvolvido, reduzindo pela metade o consumo de água no viveiro de mudas de Aracruz, para isso, houve captação de água da chuva e o tratamento dos efluentes. A Fibria faz parte do Water Footprint Network (WFN) e monitora o uso da água em todas as suas etapas produtivas para identificar oportunidades de otimização.

Outra categoria identificada refere-se às políticas ambientais. Pela análise, constatou-se que as metas da Fibria são de cunho ambiental, com destaque para a grande quantidade de excertos que fazem referência a essa dimensão do IDA. De forma complementar, a entidade também apresentou algumas políticas ambientais, como a identificação e o acompanhamento dos impactos ambientais ao longo de toda a cadeia de valor, para atuar em sintonia com a sociedade. Mais uma vez fica claro no discurso que a política da Fibria centra-se na atenção prioritária as comunidades próximas, tendo em vista que são as mais afetadas pelas operações da organização. Ainda, na perspectiva dos fornecedores, a Fibria exige que cumpram as políticas ambientais.

$\mathrm{Na}$ perspectiva das metas ambientais, verificou-se que estão alinhadas à política ambiental definida pela empresa. Como destaque apresenta-se algumas das metas identificadas na análise do Relatório de Sustentabilidade: reduzir em um terço a quantidade de terras necessárias para a produção de celulose até 2025; consolidar o negócio florestal como fonte renovável e sustentável de vida; fortalecer a atuação da Comissão Interna de Sustentabilidade (CIS), que tem como um de seus objetivos a função de monitorar a execução de compromissos assumidos pela empresa; priorizar a implantação de uma política sólida de gestão de fornecedores, realizar auditorias in loco, com foco em sustentabilidade, e elaborar de um Código de Conduta para fornecedores.

A categoria sistemas de gerenciamento ambiental, constituída dos programas ambientais e auditorias, evidenciou que a empresa possui alguns programas ambientais, como: i) Programa de Desenvolvimento Rural Territorial (PDRT) (foco: a capacitação da comunidade para gerir projetos agroflorestais sustentáveis); ii) Programa Colmeias (objetivo de contribuir para a melhoria da qualidade de vida dos apicultores); iii) Programa de Educação Ambiental (PEA) (ações para moradores, escolas, lideranças, grupos da comunidade e empresas de 
Barra do Riacho); iv) Programa de Restauração Florestal; v) Programa de Aprendizagem Florestal (qualifica mão de obra para a área de colheita florestal em parceria com o Senai e o Instituto Kolping); vi) Programa Poupança Florestal (oferece financiamentos em troca de garantia de fornecimento de madeira); vii) Programa Rede de Percepção de Odor (visa a diminuir a emissão de odor no processo industrial com base em relatos dos moradores das áreas vizinhas às fábricas.

Observou-se que a Fibria emitiu em seu Relatório de Sustentabilidade excertos sobre custos/despesas e práticas contábeis ambientais, itens que fazem parte da categoria ambiental intitulada informações financeiras ambientais. Quanto aos custos e despesas, a evidenciação centra-se na busca de novas alternativas para reduzir o volume de insumos nos processos de cozimento e branqueamento, cujo propósito é baixar os custos de produção de celulose.

Por sua vez, o discurso da empresa, no que condiz às práticas contábeis, são referentes às vendas de 207 mil hectares de terras para um fundo de investimentos brasileiro, gerando receita de $R \$ 1,65$ bilhão. A Fibria esteve envolvida em duas ações relacionadas a perdas com derivativos da Aracruz Celulose, ocorridas em 2008. Essas ações resultaram em acordos, que foram quitados no primeiro trimestre de 2013.

\subsection{Klabin}

A Klabin possui três unidades de negócios, florestal, papel (papel carta, papéis kraft e reciclados) e conversão (caixas de papelão ondulado e sacos industriais). Atualmente possui 15 unidades, distribuídas em 8 Estados brasileiros e 1 unidade na Argentina (Relatório de sustentabilidade Klabin, 2013). Pela Figura 4, observa-se que a Klabin apresentou todas as categorias ambientais que compõem o IDA no Relatório de Sustentabilidade 2013. A categoria impacto dos produtos e processos apresentou trechos referentes à utilização eficiente da água, não mencionando aspectos relativos à poluição atmosférica, poluição das águas, poluição sonora, poluição visual, resíduos e desperdícios.

Quanto à reutilização da água constata-se que a ETE garante a remoção acima de $80 \%$ de demanda bioquímica de oxigênio, assegurando o atendimento dos requisitos legais e emissões abaixo dos limites estabelecidos para o lançamento de seus efluentes, que são monitorados em todas as unidades de operação da Klabin. Esse procedimento é gerenciado por meio de relatórios e análises. Os rios que recebem os efluentes têm a qualidade da água monitorada. A Klabin também declarou que busca a redução do consumo e a utilização racional da água em todas as suas operações industriais e florestais.

$\mathrm{Na}$ categoria políticas ambientais, a empresa apresentou excertos de metas e políticas ambientais. No que concerne às metas ambientais o discurso direciona a gestão para o desenvolvimento sustentável. Ainda, as atividades desempenhadas pela organização seguem diretrizes de mudanças climáticas, cujo objetivo para 2014 é reduzir as emissões de gases do efeito estufa.

Com relação às políticas ambientais, a Klabin possui o compromisso de adotar as melhores práticas do mercado, a partir da utilização de processos ambientais e socialmente responsáveis ao longo da cadeia produtiva. O seu código de conduta reúne princípios de sustentabilidade empresarial nas esferas econômica, ambiental e social. Dessa forma, a política de sustentabilidade direciona a condução dos negócios e investimentos, considerando o crescimento sustentável e a geração de valor para todos os públicos de interesse. 


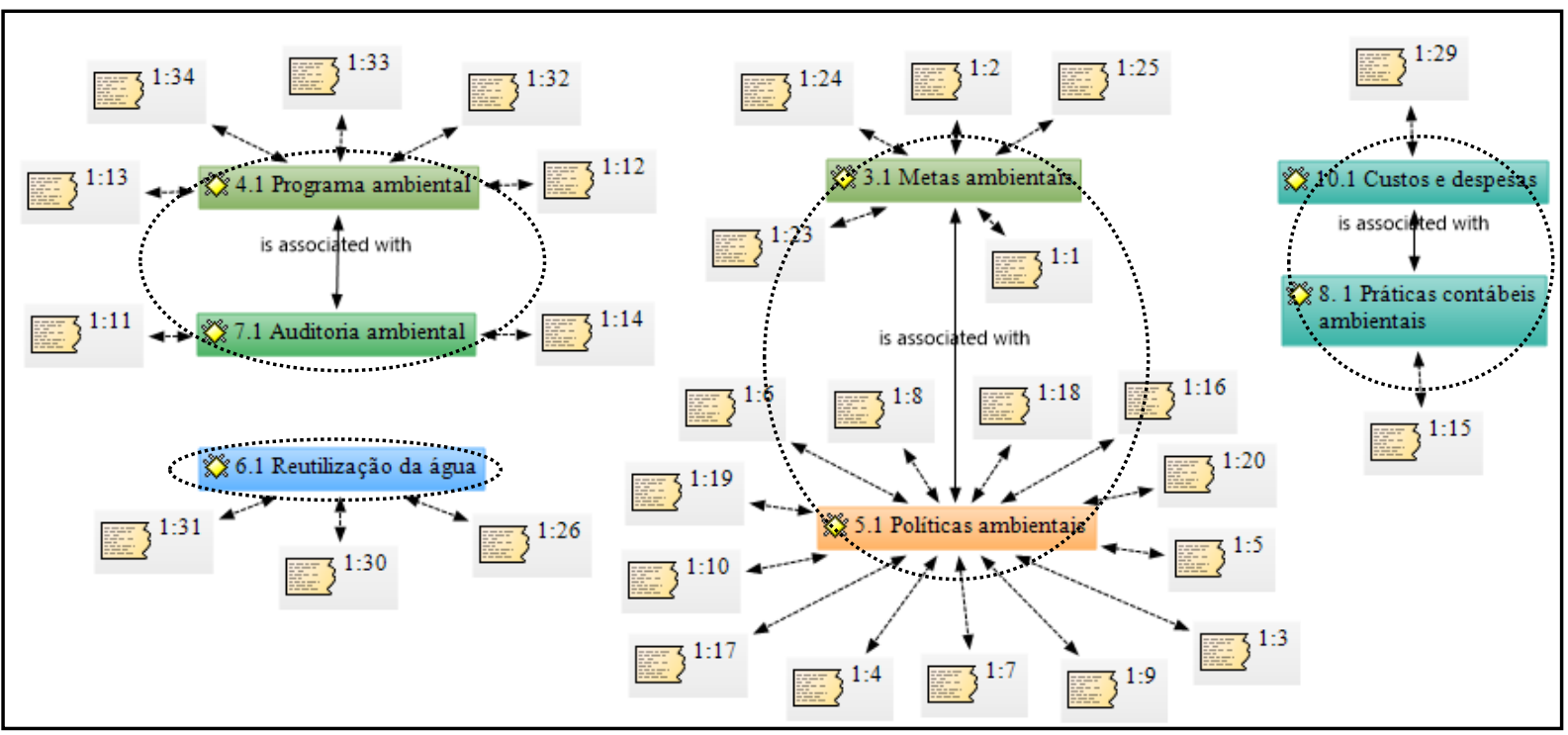

Figura 4. Aplicação do IDA na Klabin

Fonte: Os autores (2017).

$\mathrm{Na}$ categoria de sistemas de gerenciamento ambiental, a Klabin apresentou em seus relatos, evidências de auditoria ambiental e adoção de programas de gestão ambiental. $\mathrm{Na}$ perspectiva da auditoria, constata-se que uma empresa de gerenciamento de risco contratada faz o acompanhamento e auditorias nas unidades da Klabin. Em dezembro de 2013, a empresa monitorou 1992 requisitos em todas as suas unidades. A realização de auditorias internas e externas periódicas garante a correção dos dados e as evidências do sistema. Como resultado, nos últimos três anos a empresa não sofreu ação judicial, cível ou criminal com motivação ambiental.

Quanto aos programas ambientais, a Klabin possui um programa de pesquisa e conservação da fauna e da flora, com monitoramento da biodiversidade e identificação de espécies consideradas raras ou em extinção. O Programa Superar vem contribuindo para a melhoria contínua da companhia, mediante o envolvimento e a valorização das pessoas, desenvolvido na unidade Monte Alegre (PR). O Superar está presente em 14 unidades, com resultados expressivos na excelência de processos e produtos.

Com relação à categoria informações financeiras ambientais, pela análise, observam-se evidências de trechos relacionados aos custos/despesas e práticas contábeis de itens ambientais. Na ótica dos custos e despesas a Klabin recebeu multa de $\mathrm{R} \$ 2.784,52$, por produzir o corretivo de acidez (lama de cal) com teor de seu componente óxido de magnésio fora do limite de tolerância estabelecido.

Quanto às práticas contábeis de itens ambientais, a Klabin possui convênio assinado com o Governo do estado do Paraná, que prevê a divisão do ICMS proveniente das operações da nova fábrica entre 12 municípios. Ortigueira ficará com $50 \%$ e os $50 \%$ restantes serão divididos entre os 12 municípios.

\subsection{Análise Conjunta}

A partir da análise individual dos Relatórios de Sustentabilidade das empresas Celulose Irani, Cia. Melhoramentos de São Paulo, Fibria Celulose e Klabin elaborou-se a Tabela 6, que evidencia as categorias ambientais propostas pelo IDA, a composição do IDA segregado e as empresas objetos de análise neste estudo.

Das empresas analisadas somente na Cia. Melhoramentos de São Paulo não foi possível constatar trechos referentes à categoria informações financeiras ambientais. Nas demais organizações ao menos um item de cada categoria do IDA foi mencionado. 
Tabela 6

Comparação da aplicação do IDA

\begin{tabular}{|c|c|c|c|c|c|}
\hline Categorias Ambientais & Composição do IDA Segregado & 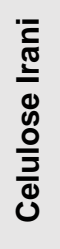 & 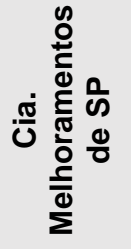 & 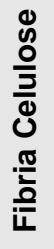 & $\frac{\frac{c}{0}}{\frac{\pi}{x}}$ \\
\hline \multirow{7}{*}{$\begin{array}{c}\text { Impacto dos Produtos e } \\
\text { Processos }\end{array}$} & 1.1 - Poluição atmosférica & $\mathrm{X}$ & & $\mathrm{X}$ & \\
\hline & 1.2 - Poluição das águas & $X$ & & & \\
\hline & 1.3 - Poluição sonora & & & & \\
\hline & 1.4 - Poluição visual & & & & \\
\hline & 2.1 - Resíduos & $\mathrm{X}$ & & $\mathrm{X}$ & \\
\hline & 2.2 - Desperdícios & $\mathrm{X}$ & & & \\
\hline & 6.1 - Reutilização da água & $X$ & $\mathrm{x}$ & $X$ & $\mathrm{X}$ \\
\hline \multirow{2}{*}{ Políticas Ambientais } & 3.1 - Metas ambientais & $\mathrm{X}$ & $\mathrm{X}$ & $x$ & $\mathrm{X}$ \\
\hline & 5.1 - Políticas ambientais & $\mathrm{X}$ & $\mathrm{X}$ & $x$ & $\mathrm{X}$ \\
\hline \multirow{2}{*}{$\begin{array}{l}\text { Sistemas de Gerenciamento } \\
\text { Ambiental }\end{array}$} & 4.1 - Programa ambiental & $\mathrm{x}$ & $\mathrm{X}$ & $x$ & $\mathrm{X}$ \\
\hline & 7.1 - Auditoria ambiental & $x$ & $X$ & $\mathrm{X}$ & $\mathrm{X}$ \\
\hline \multirow{3}{*}{$\begin{array}{c}\text { Informações Financeiras } \\
\text { Ambientais }\end{array}$} & 8.1 - Práticas contábeis ambientais & & & $\mathrm{X}$ & $\mathrm{X}$ \\
\hline & 9.1 - Reserva ambiental & & & & \\
\hline & 10.1 - Custos e despesas & $X$ & & $X$ & $\mathrm{X}$ \\
\hline
\end{tabular}

Nota. Fonte: os autores (2017).

Comparando a composição do IDA segregado (quatorze indicadores) com o diclosure ambiental constata-se que: i) Celulose Irani foi a empresa que mais evidenciou categorias do IDA, dez categorias ou $71 \%$ de evidenciação; ii) Cia Melhoramentos de São Paulo, apresentou cinco categorias ou 36\% de evidenciação; iii) Fibria Celulose, apresentou 9 categorias do IDA segregado ou $64 \%$ de evidenciação e; iv) Klabin sete categorias ou $50 \%$ de evidenciação.

Dessa forma, a partir da análise conjunta das empresas que compuseram este estudo constata-se que a composição do IDA é integrante do Relatório de Sustentabilidade das empresas pertencentes ao setor de papel e celulose. Todavia, constata-se que o nível de disclosure ambiental não é estável. Algumas empresas divulgam mais informações comparativamente a outras. Constatou-se também que as categorias políticas ambientais e sistemas de gerenciamento ambiental são as que apresentam o maior nível de evidenciação. São recorrentes em todos os relatórios analisados.

\section{CONCLUSÕES}

O objetivo do artigo consistiu em apresentar os resultados da aplicação do IDA nas empresas pertencentes ao setor de papel e celulose no Brasil. Dessa forma, o trabalho procurou contribuir empiricamente para a validação do indicador proposto por Bachmann et al. (2013), a partir de análise de conteúdo dos Relatórios de Sustentabilidade de quatro empresas: Celulose Irani; Cia Melhoramentos de São Paulo; Fibria Celulose e Klabin. Adicionalmente, discutiram-se aspectos centrados na sustentabilidade das organizações.

A partir das análises constatou-se que todas as empresas examinadas evidenciam informações ambientais. As categorias políticas ambientais e sistemas de gerenciamento ambiental são as mais divulgadas. Por outro lado, o volume de trechos e a robustez do Relatório de Sustentabilidade variam entre as organizações; constataram-se diferenças quanto ao volume de informações e ainda quanto às categorias elucidadas pelas empresas. 
Conclui-se que os achados deste estudo contribuem para: i) evidenciar como as empresas do segmento de papel e celulose reportam suas informações ambientais para os stakeholders; ii) demonstrar a aplicação do IDA a um segmento específico; iii) validar o IDA, indicador que até o momento estava restrito ao campo teórico, por não ter sido aplicado empiricamente; iv) fortalecer teórica e empiricamente os estudos ambientais.

Todavia, na análise dos resultados deve-se ponderar que os achados são restritos aos Relatórios de Sustentabilidades examinados e ao segmento de papel e celulose, portanto, não podem ser generalizados. Ainda, como limitação, adverte-se que o estudo refere-se ao ano de 2013. Logo é possível que em anos anteriores as empresas analisadas apresentassem outros aspectos de disclosure ambiental.

Sugere-se que pesquisas futuras possam ser realizadas em outros segmentos ou que a janela de análise contemple maior número de anos, a fim de consolidar a validação da construção teórica proposta por Bachmann et al. (2013). Além disso, recomenda-se a replicação deste estudo para que comparações possam ser realizadas.

\section{REFERÊNCIAS}

Aaker, D. A. (2001). Administração estratégica de mercado (7a ed.). Porto Alegre: Bookman.

Ashcroft, P. A. (2012). Extent of environmental disclosure of US and Canadian firms by annual report location. Advances in Accounting, 28(2), 279-292.

Bachmann, R. K., Carneiro, L. M., \& Espejo, M. M. dos S. B. (2013). Evidenciação de informações ambientais: proposta de um indicador a partir da percepção de especialistas. Revista de Contabilidade e Organizações, 7(17), 36-47.

Bardin, L. (2004). Análise de conteúdo (3a ed.). Lisboa: Edições 70.

Beuren, I. M., Santos, V. dos, \& Gubiani, C. A. (2013). Informações ambientais evidenciadas no relatório da administração pelas empresas do setor elétrico listadas no ISE. BASERevista de Administração e Contabilidade da Unisinos, 10(1), 55-68.

BM\&FBovespa. (2014). Índice de Sustentabilidade Empresarial (ISE).

Borba, J. A., Rover, S., \& Múrcia, F. D. (2006). Do Brazilian corporations disclose environmental information? Evidences from financial statement published in the New York Securities Exchange and in the Bolsa de Valores de São Paulo. In Asian Pacific Conference, Maui,18.

Borges, A. P., Rosa, F. S. D., \& Ensslin, S. R. (2010). Evidenciação voluntária das práticas ambientais: um estudo nas grandes empresas brasileiras de papel e celulose. Produção On Line, 20(3), 404-417.

Comissão de Valores Mobiliários (CVM). (1987, 28 de dezembro). Parecer de orientação $n^{\circ}$ 15, de 28 de dezembro de 1987.

Conselho Federal de Contabilidade (CFC). (2004). Resolução CFC no 1.003/04. Aprova a NBC T 15 - Informações de natureza social e ambiental. Brasília, DF.

Costa, R. S., \& Marion, J. C. (2007). A uniformidade na evidenciação das informações ambientais. Revista Contabilidade e Finanças, 18(43), 20-33.

Dalmoro, M., Venturini, J. C., \& Pereira, B. A. D. (2009). Marketing verde: responsabilidade social e ambiental integradas na envolvente de marketing. Revista Brasileira de Gestão de Negócios, 11(30), 38-52.

Fauzi, H. (2009). Corporate social and financial performance: empirical evidence from American companies. Globsyn Management Journal, Forthcoming.

Gasparino, M. F., \& Ribeiro, M. de S. (2007). Análise de relatórios de sustentabilidade, com ênfase na GRI comparação entre empresas do setor de papel e celulose dos EUA e Brasil. Revista de Gestão Social e Ambiental, 1(1), 102-115. 
Gray, R., \& Bebbington, J. (2001). Accounting for the Environment. Sage.

Instituto dos Auditores Independentes do Brasil (IBRACON). (1996). NPA 11 - Normas e procedimentos de auditoria - Balanço e ecologia. São Paulo, Ibracon.

Kassai, J. R., Ha, H., \& Carvalho, L. N. (2011). Diálogo IFRS e GRI para o Desenvolvimento Sustentável. In Encontro da Anpad, Rio de Janeiro, 35.

Lei.$^{\circ}$ 6.404, de 15 de dezembro de 1976 atualizada (1976, 15 de dezembro). Dispõe sobre as sociedades por ações. Diário Oficial da República Federativa do Brasil. Brasília, DF.

Lei n.o 11.638, de 28 de dezembro de 2007 (2007, 28 de dezembro). Altera e revoga os dispositivos da Lei n. ${ }^{\circ} 6.404 / 76$ e Lei $n .{ }^{\circ}$ 6.385/76 e estende as sociedades de grande porte disposições relativas a elaboração de divulgação das Demonstrações Financeiras. Diário Oficial da República Federativa do Brasil. Brasília, DF.

Lu, Y., \& Abeysekera, I. (2014). Stakeholders' power, corporate characteristics, and social and environmental disclosure: evidence from China. Journal of Cleaner Production, 64, 426436.

Momin, M. A. (2013). Social and environmental NGOs' perceptions of corporate social disclosures: the case of Bangladesh. Accounting Forum, 37(2), 150-161.

Múrcia, F. D. R., Rover, S., Lima, I., Fávero, L. P. L., \& Lima, G. A. S. F. de. (2008). 'Disclosure Verde' nas demonstrações contábeis: características da informação ambiental e possíveis explicações para a divulgação voluntária. Contabilidade, Revista UnB Contábil, 11, 260-278.

Múrcia, F. D. R., \& Santos, A. (2009). Fatores determinantes do nível de disclosure voluntário das companhias abertas no Brasil. Revista de Educação e Pesquisa em Contabilidade, 3(2), 72-95.

Nascimento, A. R. do, Santos, A. dos, Salotti, B., \& Múrcia, F. D. (2009). Disclosure social e ambiental: análise das pesquisas científicas veiculadas em periódicos de língua inglesa. Contabilidade Vista \& Revista, 20(1), 15-40.

Nossa, V. (2002). Disclosure ambiental: uma análise do conteúdo dos relatórios ambientais de empresas do setor de papel e celulose em nível internacional. Tese de Doutorado, Universidade de São Paulo.

Porter, M. E. (1993). Estratégia competitiva: técnicas para análise de indústrias e da concorrência. Rio de Janeiro: Campus.

Relatório de Sustentabilidade Celulose Irani. (2013). Recuperado em 10 de outubro de 2014, de http://extranet.irani.com.br/relatorio-de-sustentabilidade-2013/

Relatório de Sustentabilidade Cia Melhoramentos de São Paulo. (2013). Recuperado em 10 de outubro de 2014, de https://drive.google.com/file/d/OB_IC4QOQUPzLZWR1RjVscUluR0U/edit?usp=sharing

Relatório de Sustentabilidade Fibria Celulose. (2013). Recuperado em 10 de outubro de 2014, de http://www.fibria.com.br/relatorio2013/shared/relatorio-de-2013-firmes-no-rumo7abr2014.pdf

Relatório de Sustentabilidade Klabin (2013). Recuperado em 10 de outubro de 2014, de http://rs.klabin.com.br/

Ribeiro, M. S. (1992). Contabilidade e meio ambiente. Dissertação de Mestrado, Universidade de São Paulo.

Rover, S., Múrcia, F. D., Borba, J. A., \& Vicente, E. F. R. (2008). Divulgação de informações ambientais nas demonstrações contábeis: um estudo exploratório sobre o disclosure das empresas brasileiras pertencentes a setores de alto impacto ambiental. Revista de Contabilidade e Organizações, 2(3), 53-72. 
Roumeliotis, L. P. C., \& Alperstedt, G. D. P (2014). Princípios e indicadores ambientais nos relatórios de sustentabilidade das empresas de energia elétrica de Santa Catarina: uma análise baseada na Global Reporting Initiative. In Encontro da Anpad, Rio de Janeiro, 38.

Schaltegger, S., \& Burritt, R. (2000). Contemporary environmental accounting: issues, concepts and practice. Greenleaf Publishing.

Souza, M. A. de, Rásia, K. A., \& Jacques, F. V. da S. (2010). Evidenciação de informações ambientais pelas empresas integrantes do índice de sustentabilidade empresarial - ISE. Revista de Contabilidade e Controladoria, 2(1), 51-139.

Tachizawa, T. (2002). Gestão ambiental e responsabilidade social. São Paulo: Atlas.

Yamamoto, M. M., \& Salotti, B. M. (2006). Informação contábil: estudos sobre a sua divulgação no mercado de capitais. São Paulo: Atlas.

Zeng, S. X., Xu, X. D., Dong, Z. Y., \& Tam, V. W. Y. (2010). Towards corporate environmental information disclosure: an empirical study in China. Journal of Cleaner Production, 18,1142-1148.

Zhongfu, Y., Jianhui, J., \& Pinglin, H. (2011). The study on the correlation between environmental information disclosure and economic performance with empirical data from the manufacturing industries at Shanghai Stock Exchange in China. Energy Procedia, 5, 1218-1224. 